\title{
Trafalgar: investigación de las fuentes documentales
}

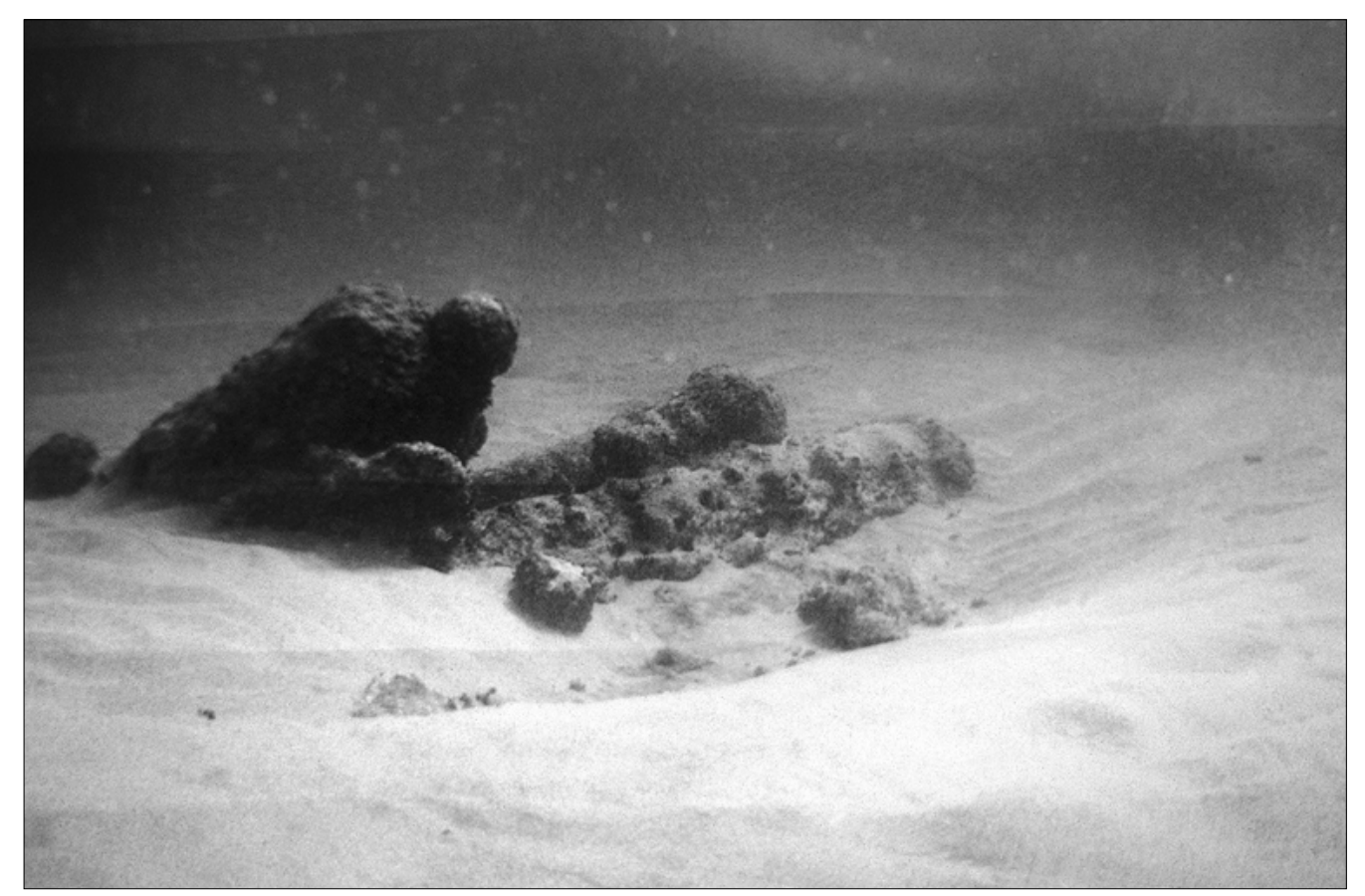

\section{Lourdes Márquez Carmona}

Centro de Arqueología Subacuática del IAPH

\section{Resumen}

Se efectúa un análisis de la información proporcionada por las fuentes documentales sobre los naufragios producidos en el litoral de Cádiz y Huelva, a consecuencia de la Batalla de Trafalgar y del fuerte temporal que le sobrevino, siendo uno de los objetivos principales delimitar espacialmente las posibles zonas de hundimiento. En este famoso combate naval se enfrentaron el 21 de octubre de I 805 frente al Cabo de Trafalgar, en el Sur de la Península Ibérica un total de 74 barcos, una parte, bajo pabellón inglés a las órdenes del Almirante Nelson y otra, formada por la escuadra aliada his- pano-francesa comandada por su homólogo francés Villeneuve.

Esta investigación documental es una de las fases del Proyecto Trafalgar emprendido por el Centro de Arqueología Subacuática, dependiente del Instituto Andaluz del Patrimonio Histórico, cuyo objetivo principal es el análisis, estudio y evaluación de los restos sumergidos a consecuencia de la batalla, mediante una metodología arqueológica, buscando establecer las medidas necesarias para una correcta investigación, protección, conservación y difusión de una parte importante de nuestro pasado histórico.

\section{Palabras claves}

Arqueología subacuática / Batallas navales / Naufragios / Trafalgar Batalla de 


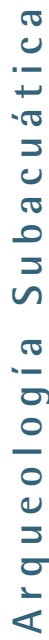

\section{Introdución}

Durante el siglo XVIII se produjeron continuos enfrentamientos entre las distintas potencias europeas por mantener el dominio en el mar, para así conseguir el control de las rutas comerciales hacia sus colonias. Es la época en la que los grandes "navíos de línea" que se caracterizaban por una formación en fila unidos lo más estrechamente posible proa con popa para presentar batalla ante una escuadra enemiga, dominaban los océanos y competían por ser más rápidos y mejores.

El Tratado de Amiens firmado el 25 de marzo de 1802, devolvió a España la paz tras unos años de guerras marítimas con Inglaterra. Sin embargo, no fue muy duradera, ya que el continuo hostigamiento de los navíos ingleses hacia la armada española provocó, sin que hubiera existido una ruptura previa, de nuevo el estado de guerra entre ambas monarquías. Este enfrentamiento se va a materializar en la denominada BATALLA DE TRAFALGAR, combate naval mantenido el 21 de Octubre de 1805 entre la flota aliada hispano-francesa y la flota británica en aguas del Atlántico, frente a las costas españolas, en el cabo de Trafalgar.

Este combate naval ha suscitado en el transcurso de estos dos siglos numerosos estudios, con un carácter puramente histórico. Numerosos investigadores han escrito sobre los antecedentes de la batalla, la situación política de Europa, las distintas alianzas entre las potencias europeas, la situación de la marina española a principios del s. XIX, los movimientos de la escuadra inglesa desde el mar Mediterráneo hasta el mar del Caribe en busca de la escuadra combinada, así como del encuentro final entre las dos armadas frente al Cabo de Trafalgar, situado en el Sur de la Península Ibérica. El desarrollo del combate y la táctica naval empleada, han sido también dos temas muy tratados por los estudiosos, especialmente por los investigadores de la Historia de la Marina Española.

No obstante, la presencia de restos arqueológicos localizados por azar en diferentes puntos del litoral gaditano y onubense -especialmente cañones-, así como las noticias de la existencia de determinados naufragios de barcos, supuestamente pertenecientes a las escuadras que intervinieron en la batalla, hace necesaria la realización de un proyecto que permita mediante una metodología arqueológica y unas técnicas específicas, confirmar la existencia y cronología de aquellos hallazgos que tradicionalmente se han vinculado al combate de Trafalgar. De esta forma, y para analizar los hechos desde un punto de vista arqueológico, el Centro de Arqueología Subacuática, dependiente del Instituto Andaluz de Patrimonio Histórico se planteó el presente proyecto que tiene como objetivo principal a través del análisis, estudio y evaluación de los restos sumergidos como consecuencia de la batalla de Trafalgar así como del temporal que se desencadenó el día después, establecer las medidas necesarias para una correcta investigación, protección, conservación y difusión de una parte importante de nuestro pasado histórico.
Este Proyecto de Investigación, necesitaba el planteamiento de una fase previa documental que profundizase en la realidad de este enfrentamiento naval entre las dos escuadras. Solamente mediante la consulta de la documentación original que lo suscitó, así como de las publicaciones surgidas a lo largo de los siglos XIX y $X X$, es posible clarificar lo que realmente sucedió a los navíos naufragados.

\section{Contextualización histórica}

El golpe de Estado de 18 de brumario ( 10 de noviembre de 1799) supuso la llegada al poder de $\mathrm{Na}$ poleón Bonaparte, acentuándose la influencia francesa en España. Rota la paz de Amiens el 12 de mayo de 1803, el monarca español Carlos IV se vio presionado por el emperador francés para conseguir su apoyo., Este pretendió conservar la neutralidad española, pero se vio obligado a no cumplirla al auxiliar a Francia en distintas acciones. Inglaterra no podía consentir esta situación y sin previa declaración de guerra apresó 4 fragatas que provenían de América cargada de caudales. Eran las denominadas Medea, Clara, Mercedes y Fama, que venían de Montevideo a España cargadas con 1.307.634 pesos fuertes para el Rey y 3.428 .519 para particulares. Fueron atacadas el 5 de Octubre de 1804 cerca del Cabo Santa María, en la costa de Portugal, por cuatro fragatas inglesas, siendo volada durante la contienda la Mercedes y llevadas las restantes a los puertos ingleses de Plimouth y Portsmouth. La reacción de España no tardó: Carlos IV declaró la guerra a Inglaterra el 12 de Diciembre de 1804 mediante un Memorandum que dirigió a todas las naciones de Europa, en el que justificaba los hechos. Poco después se acordó en la capital de Francia, entre el embajador español Gravina y el ministro Decrès un convenio de operaciones marítimas.

Napoleón planeaba invadir Inglaterra con sus tropas, pero para conseguirlo necesitaba la ayuda de las fuerzas navales españolas, ya que éstas aumentarían el poder de su escuadra naval para intentar dominar el Canal de la Mancha.

Pero el principal error de Napoleón fue nombrar al protegido del Ministro Decrés, el Almirante Villeneuve, como comandante en jefe, porque no poseía actitudes para responsabilizarse del mando de una gran escuadra y hacer cumplir las órdenes del emperador francés. Las pocas cualidades para el mando del almirante francés, en contraposición con el carisma que poseía entre sus marinos su homólogo de la escuadra inglesa, Lord Nelson, junto con el hecho de que la situación de la Marina española al comenzar el S. XIX no era mucho mejor que en el país vecino, fueron factores determinantes del desastre de Trafalgar. Los barcos estaban en mal estado, algunos se habían entregado a la Marina del país galo (por el Tratado de San Ildefonso firmado el uno de Octubre de 1800 el gobierno español entregó seis navíos: Conquistador, Pelayo, San Genaro, San Antonio, Intrépido y Atlante) 
y muchos se pudrían en los Arsenales por la falta de carena. Al iniciarse el conflicto bélico, pocos recursos tenían los Arsenales españoles para armar los navíos necesarios con los cuales hacer frente en igualdad de condiciones a la Marina Inglesa.

\section{Objetivos}

Los objetivos a cumplir en esta fase documental fueron los siguientes:

- Contextualización de la batalla, mediante el estudio de la situación política de Europa, del papel de las potencias navales europeas (Inglaterra, Francia y España), del potencial naval de cada una de ellas y de las características armamentísticas de cada navío .

- Conocimiento de lo acontecido en la Batalla de Trafalgar a través de la documentación oficial generada a consecuencia de la misma, tanto de los partes oficiales de cada navío, como de los documentos relativos a las labores de rescate y auxilio de los mismos, publicados algunos de ellos en periódicos de la época, como es el caso de "La Gazeta de Madrid".

- Recopilación bibliográfica de la mayor parte de la documentación publicada hasta nuestros días sobre el combate naval de Trafalgar.

- Recopilación de información acerca de los materiales arqueológicos subacuáticos adscritos a la Batalla de Trafalgar y posterior análisis comparativo con los puntos que las fuentes documentales indican como posibles zonas de naufragios.

- Análisis, valoración y síntesis de la información obtenida.

- Delimitación espacial de posibles zonas de naufragios.

- Informatización de todos los datos recopilados mediante la creación de:

- Base de datos de la información bibliografica obtenida.

- Base de datos que contenga información sobre los navíos naufragados.

\section{Fuentes de localización}

Durante el tiempo previsto para la realización de este proyecto de investigación documental, se han consultado distintos centros archivísticos y bibliotecarios localizados en el área de la Bahía de Cádiz. En ello se ha utilizado documentación de diversa índole según las características del centro que custodia la información: Actas Capitulares, Actas de Conferencias de la Junta Municipal de Cádiz, Protocolos Notariales del Departamento de Marina de San Fernando, Derroteros, Mapas, Monografías, Publicaciones Seriadas.
El listado de las instituciones en cuyos fondos hemos investigado es el siguiente:

- Archivo Provincial de Cádiz

- Archivo Histórico Municipal de Cádiz

- Archivo Histórico Municipal de San Fernando

- Archivo Histórico Municipal de El Puerto de Santa María

- Biblioteca del Almirante Lobo (San Fernando)

- Biblioteca del Casino Gaditano (Cádiz)

- Biblioteca Municipal de Cádiz

- Biblioteca Provincial de Cádiz

- Biblioteca del Real Observatorio de Marina de San Fernando

- Biblioteca de Temas Gaditanos (Cádiz)

\section{Metodología}

La metodología seguida en este trabajo de recopilación documental sobre los sucesos que acontecieron durante la Batalla de Trafalgar, se desarrolló en las siguientes fases generales:

\section{Análisis documental}

Lo documentación encontrada en las distintas bibliotecas y archivos consultados ha sido sometida a un proceso de análisis, al objeto de hacer más fácilmente recuperable la información. Con todas las referencias documentales encontradas sobre las posibles zonas de hundimiento de los barcos, se ha elaborado un listado de las mismas para cada respectivo navío. Éste se encuentra dividido en tres apartados: nombre del navío, zona de hundimiento y fuente informativa. Aunque hay que decir que no existe unanimidad de las fuentes consultadas, ya que para un mismo navío, contamos con referencias de distintas zonas para su área de naufragio.

Por otro lado, se hizo necesario para garantizar la rapidez de acceso a la información, plantearse la informatización de todos los datos obtenidos.

De este modo, el proyecto de informatización se estructura en dos módulos diferenciados:

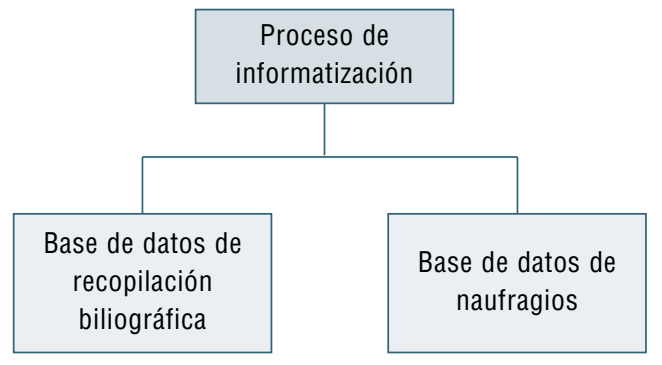

- Base de Datos de Recopilación Bibliográfica: Con los documentos secundarios obtenidos se ha 


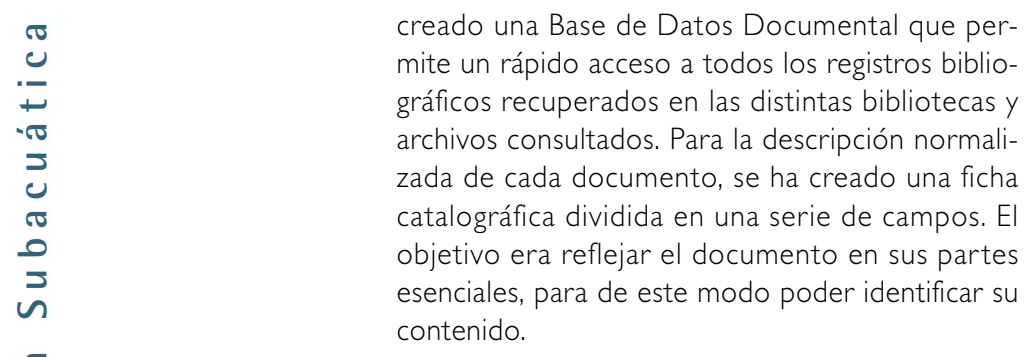

- Base de Datos de Naufragios: Contiene toda la información relativa a los navíos naufragados, documentados a partir de la información textual consultada. Los campos que componen la estructura de esta base de datos quedan reflejados en la siguiente ficha:

\begin{tabular}{|c|c|}
\hline NOMBRE & Nombre del Navío \\
\hline CLASE & Categoría del navío (en función del porte). \\
\hline NACIONALIDAD & Nación a la que pertenecía: española, francesa o inglesa. \\
\hline ARSENAL DE CONSTRUCCIÓN & Astillero en el que fue construido \\
\hline AÑO DE BOTADURA & Fecha en que comienza a prestar servicio. \\
\hline SISTEMA CONSTRUCTIVO & Sistema de construcción naval empleado. \\
\hline PORTE & $\begin{array}{l}\text { Número de cañones. Este campo lleva asociada otra } \\
\text { pequeña base de datos que contiene información } \\
\text { acerca de su distribución. }\end{array}$ \\
\hline ARQUEO & Volumen o capacidad del navío. \\
\hline ESLORA & Longitud del navío. \\
\hline MANGA & Anchura del navío. \\
\hline PUNTAL & $\begin{array}{l}\text { Altura medida en el centro de la eslora del navío, } \\
\text { desde la quilla hasta las diversas cubiertas. }\end{array}$ \\
\hline QUILLA & $\begin{array}{l}\text { Medida de la quilla, que es la pieza donde van } \\
\text { asentadas la varengas o cuadernas del navío. } \\
\text { Es como la espina dorsal del mismo. }\end{array}$ \\
\hline PLAN & $\begin{array}{l}\text { Piso más bajo del navío o la parte superior del forro } \\
\text { interior que limita horizontalmente el doble fondo. }\end{array}$ \\
\hline ESCUADRA & $\begin{array}{l}\text { Escuadra en la que se alineaba durante el combate: } \\
\text { Escuadra Combinada (franco-española) o Escuadra } \\
\text { Inglesa. }\end{array}$ \\
\hline DIVISIÓN & Cuerpo al que pertenecía en la formación de combate. \\
\hline COMANDANTE & Nombre del comandante del navío. \\
\hline $\mathrm{N}^{0}$ DE TRIPULANTES & $\begin{array}{l}\text { Número de tripulación que estaba enrolada } \\
\text { previamente al combate. }\end{array}$ \\
\hline ZONA DE HUNDIMIENTO & Lugar en el que se produjo el naufragio. * \\
\hline CAUSA DEL HUNDIMIENTO & $\begin{array}{l}\text { Motivo del naufragio: Echado a pique por los ingleses, } \\
\text { incendiado, hundido a causa del temporal. }\end{array}$ \\
\hline FUENTE INFORMATIVA & $\begin{array}{l}\text { Documentación de la que han sido extraídos los } \\
\text { datos acerca de la zona de hundimiento. }\end{array}$ \\
\hline NOTAS & Nota informativa sobre cualquier dato de interés. \\
\hline
\end{tabular}

* Es necesario aclarar que, según las fuentes consultadas, no existe unanimidad con respecto a la zona de hundimiento
Actualmente este apartado se encuentra en el proceso de alimentación de estas dos Base de Datos con toda la información analizada.

\section{Análisis histórico}

Este sección esta compuesta por dos grandes bloques temáticos:

\section{Situación de la Marina Española durante el siglo XVIII:}

El objetivo de identificar los posibles restos subacuáticos pertenecientes a navíos naufragados, hizo necesario dedicar una fase de nuestro Proyecto a realizar un análisis retrospectivo de la situación de la Marina Real Española durante el transcurso del siglo XVIII. Este siglo supuso una continua lucha de las potencias europeas por mejorar sus sistemas de construcción naval con el fin de hacer predominar su poder en las rutas comerciales marítimas. El intercambio entre los países europeos de especialistas en este sector fue una realidad. En el territorio español, este siglo supuso un gran avance en la construcción naval, tanto por la normalización de la fabricación de los barcos, como por las numerosas innovaciones que se introdujeron para mejorar la calidad de los mismos. Hasta la fecha la construcción de buques había permanecido en manos de particulares, a los cuales el gobierno les otorgaba concesiones. Al hacerse cargo el Estado, todo el procedimiento se vio mejorado, desde la construcción de establecimientos para la fabricación de navíos, hasta la introducción de distintas innovaciones tecnológicas, pasando por la evolución de los sistemas constructivos que desarrollaron diferentes ingenieros navales bajo la protección de ministros de marina como Patiño y Ensenada, cuya única pretensión era el desarrollo de este cuerpo.

Por ello los epígrafes tratados en este apartado han sido los siguientes

- Astilleros: Los astilleros pertenecientes a la corona española, ubicados tanto en la Península Ibérica como en la colonias americanas, vieron partir de sus gradas los buques que prestarían servicio a la Armada Española, entre ellos, muchos de los que participaron en el combate de Trafalgar.

Se han encontrado referencias de los astilleros donde fueron construidos algunos de los navíos naufragados en Trafalgar, junto con su año de botadura.

- Sistemas de Construcción Naval: La fabricación de barcos pasó a ser normalizada y organizada por el Gobierno que contrató a distintos ingenieros, entre ellos ingleses y franceses, para conseguir este objetivo, construyéndose en serie algunos de los barcos. A través de la documentación consultada se han documentado los distintos sistemas mediante los cuales fueron construidos algunos de los navíos participantes en el combate.

- Unidades de Construcción Naval: El estudio de este tema se hizo necesario para aclarar las unidades 
y medidas empleadas en la época, lo cual proporciona una visión más clara de las dimensiones de un navío, al poder convertir en medidas actuales las unidades que las Ordenanzas Militares mandaban utilizar, como por ejemplo el "Pie de Burgos".

- Innovaciones tecnológicas: El campo de la construcción naval experimentó diversas innovaciones tecnológicas, entre ellas el forrado con planchas de cobre del casco de los navíos, para alcanzar el mayor grado de estanqueidad posible, evitando al mismo tiempo la acción corrosiva del temido Teredo Navalis o "Broma" ( molusco bivalvo que horada y penetra en la estructura de madera de los buques). Consultando la información encontrada, se ha constatado cómo algunos de los barcos que sobrevivieron a la batalla, pasaron por las gradas del Arsenal de La Carraca de San Fernando (Cádiz), para reparar los daños producidos en las planchas de cobre por los impactos de los proyectiles lanzados por la escuadra inglesa. Este dato documental será de gran utilidad para realizar la valoración arqueológica de los distintos pecios que se localicen, ya que en ellos aun pueden existir restos del forro de cobre.

- La distribución interna de un navío y los sistemas de ornamentación, como es el caso de la pintura de Ordenanza, son otros de los temas tratados.

Hay que decir que se ha encontrado una referencia sobre la pintura del casco de uno de los buques naufragados en el litoral onubense, a través de los partes oficiales que se redactaron para informar de las labores de rescate:

"Recuperado en la Costa de Castilla, cuatro pedazos de un costado del navío Trinidad, pintado a franjas encarnadas y negras con 18 o 20 cañones embragados".

- Distribución de la artillería de un navío: El proceso de normalización del Cuerpo de Marina no sólo afectó al sistema de construcción naval, sino también a la ordenación de la Artillería, que pasó a ser regulada por una serie de ordenanzas, llamándose por ello "Artillería de Ordenanza". Contamos con los datos de los cañones que portaban los distintos navíos de las tres escuadras navales que participaron en Trafalgar, pero a través de esta sección se ha obtenido información sobre el número de cañones y los tipos de calibres que las Ordenanzas de la Marina Española disponían para artillar en los navíos, clasificados en cuatro categorías, según el porte.

Desde un punto de vista arqueológico hay que mencionar que cañones y proyectiles son de los restos materiales que pueden conservarse durante bastante tiempo en el medio subacuático, además de ser un buen instrumento de datación por las inscripciones y leyendas que puedan conservar.

\section{Desarrollo de la Batalla de Trafalgar}

En el año I 804 España, debido a la posición de neutralidad en la que se mantenía, solo poseía armados un reducido número de navíos. El 4 de Enero de I 805 firmó con Francia un convenio naval, mediante

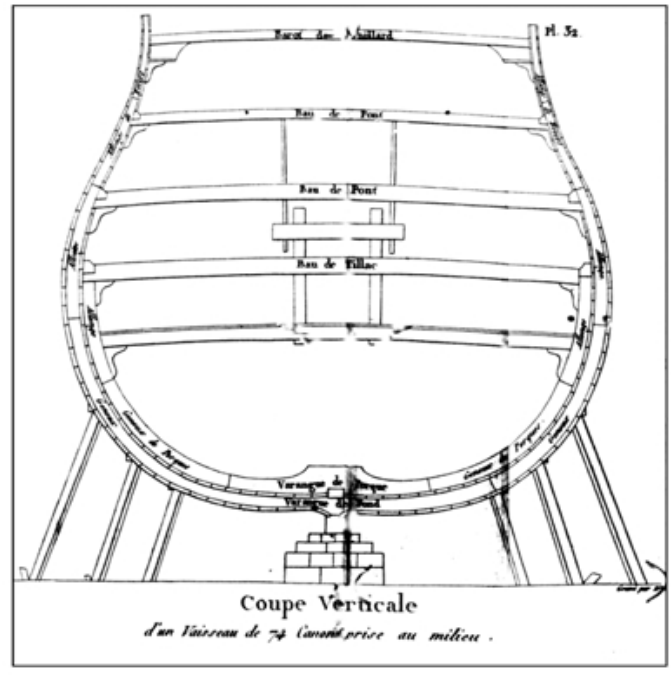

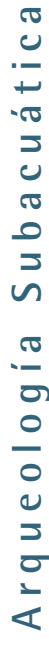

el cual se comprometía España a armar 8 navíos y 4 fragatas en Ferrol, 12 navíos en Cádiz y 6 en Cartagena. Gravina, Almirante de la Escuadra española, era consciente de las malas condiciones en las que se hallaban la mayoría. Una parte de todos esos navíos pertrechados en los 3 departamentos de El Ferrol, Cartagena y Cádiz, se unirían más tarde a la escuadra francesa de Villeneuve, formando la flota combinada que poco tiempo después sucumbiría frente al Cabo de Trafalgar.

Hay que decir, que este combate supuso el tan esperado encuentro del Almirante Nelson, comandante en jefe de la escuadra inglesa, con la escuadra combinada, a la que persiguió y buscó sin éxito durante varios meses por el Mediterráneo y colonias americanas.

A través de las fuentes de información consultadas tenemos documentada perfectamente los preliminares y el desarrollo de la batalla, desde los movimientos de la escuadra inglesa hasta el enfrentamiento final de las dos escuadras enemigas el día 21 de octubre de las dos escuadras enemigas frente al Cabo Trafalgar, situado en el Sur de la Península Ibérica.
Herbin de Halle, $P$ (I8|3). Des bois propes au service des arsenaux. París. Sección transversal de un navío de 74 cañones

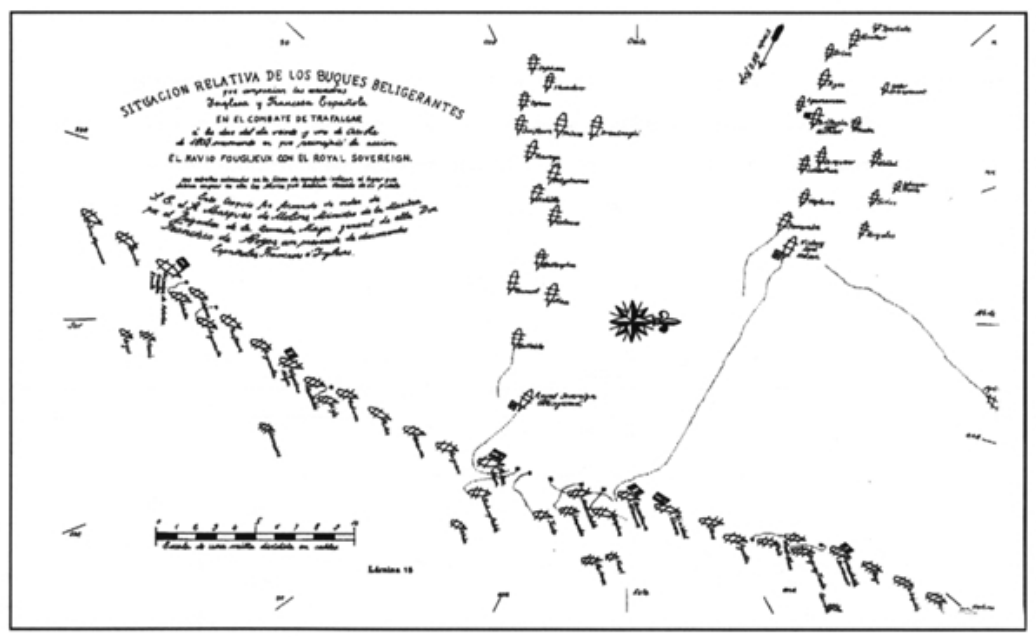

Marliani, M. (1850). Combate de Trafalgar. Plano de situación de la Batalla. 


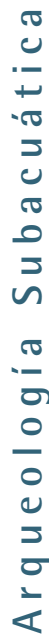

Villeneuve recibió noticias de que Nelson se hallaba en las Islas Barbados, donde se le habían unido cuatro navíos de línea más. Pero temiendo que la escuadra inglesa fuese superior de lo que en realidad era, ordenó el regreso a Europa, a cuya decisión se opuso sin éxito Gravina, por creer que era una huida. No obstante, las órdenes de Villeneuve eran que si no se le agregaba la Escuadra de Brest, debía reunirse con ella, poniendo rumbo antes al Ferrol al objeto de incorporar las divisiones francesa y española fondeadas en este puerto, todo ello con el fin de que una poderosa escuadra naval entrara en el Canal de la Mancha y de este modo permitir el desembarco de las tropas francesas en Inglaterra, que era el objetivo fundamental de los planes de Napoleón.

Nelson al ser informado de la partida de los enemigos regresó a Europa, llegando más rápidamente que los aliados. Al no encontrarlos en el puerto de Cádiz se dirigió a Gibraltar, donde se le unieron los navíos del Almirante Collingwood. La escuadra inglesa de Calder que bloqueaba el puerto de El Ferrol recibió también órdenes de agregarse a esta escuadra. Sin embargo, se encontraron con los navíos franco-españoles que regresaban a Europa. Ambas se enfrentaron frente al Cabo Finisterre el 22 de julio de 1805 En este combate los ingleses consiguieron apresar dos navíos españoles: el Firme y el San Rafael, que fueron llevados a Gibraltar, sin que los franceses hicieran nada por recuperarlos. El combate de Finisterre significó el enfado de Napoléon hacia Villeneuve, y una baja de moral entre los marinos españoles y franceses. El marino francés dejó de ser hombre de confianza del emperador, y los marinos de las naciones aliadas se achacaron recíprocamente el fracaso de la acción.

En su estancia en los puertos de Galicia la escuadra combinada aumentó su número, a pesar de dejar en la Ría de Vigo el Atlas, el España y el América, debido a su mal estado. Villeneuve incorporó a cinco navíos franceses más, y Gravina a ocho. El 13 de agosto la Escuadra Combinada una vez reunificada, salieron de la Ría de Ares, pero a la altura del Cabo Ortegal, Villeneuve es avisado por un buque de nacionalidad danesa de la proximidad de los ingleses. Decide cambiar de ruta y poner rumbo hacia Cádiz, puerto donde fondea la flota el 20 de agosto. Desde esta fecha hasta el 19 de octubre, la escuadra española hizo los últimos preparativos previos al combate de Trafalgar, terminándose de armar navíos en el Arsenal de la Carraca de San Fernando. La escuadra española aumentó con la unión de 6 nuevos navíos a un número de 15 , de unas condiciones militares muy desiguales.

Napoleón viendo como se alargaba la estancia enfurecía cada vez más, al ver peligrar sus planes de partir la escuadra de Cádiz y unirse con la escuadra española fondeada en Cartagena para dominar el Mediterráneo. De este modo Napoleón decidió sustituir a Villeneuve por Almirante Rosilly, más apto para el cargo de cumplir sus proyectos navales. Avisado por su amigo Decrès de la ira del emperador y de su inmediata destitución, Villeneuve, decidió para recuperar la estima de Napoleón que los barcos salieran de la Bahía de Cádiz, el día 7 de octubre, aprovechando el viento fa- vorable del Este. Ante la postura contraria de los marinos españoles, se celebró un Consejo de Guerra el día siguiente, el día 8 , a bordo del Bucentaure, buque insignia francés, desaconsejando los oficiales españoles la salida entre otras razones, ante la previsión de la llegada de una borrasca, marcada por la bajada de los barómetros. El resultado de aquella reunión fue que se aguardase en el puerto y se cancelase la señal de partir. Sin embargo, Villeneuve fue prevenido por el ministro de marina Decrès, de que Napoleón había enviado al Almirante Rossilly para sustituirlo en el mando. Por ello pensó que recuperaría la confianza del emperador si salía a combatir. Finalmente, el día 18 de octubre dio orden de "dar a la vela" a la Escuadra Combinada.

El almirante francés había sido informado erróneamente de las fuerzas navales al mando de Nelson: un total de 18 navíos, por lo que salió de la Bahía convencido de su superioridad numérica. Sin embargo, su alegría duró poco, porque Nelson contaba realmente con una fuerza de 27 navíos, cuatro fragatas y 2 balandras, con más de 2000 piezas de cañones.

Para igualar las fuerzas de la escuadra combinada, había sido previsto intercalar los navíos españoles con los franceses. De manera que la Armada quedó dispuesta en cuatro cuerpos: vanguardia, centro, retaguardia y escuadra de observación.

\section{Escuadra Hispano-francesa:}

\section{Vanguardia:}

- Plutón (74 cañones)

- Monarca (74 cañones).

- Fongueux (74 cañones).

- Santa Ana (120 cañones).

- Indomptable (80 cañones).

- San Justo (74 cañones).

- Intrépide (74 cañones).

- Fragata Rhin (40cañones).

Capitán Cosmao (F)*

Capitán Teodoro Argumosa (E)

Capitán Baudoin (F).

Capitán Gardoqui (E).

Teniente General Alava.

Capitán Hubert (F).

Capitán Gastón (F)

Capitán Infernet (F).

Capitán Chesnan (F).

Centro:

- Redouptable (74 cañones). Capitán Lucas (F).

- San Leandro (64 cañones). Capitán Quevedo (E).

- Neptune (80 cañones).

Capitán Maistral (F).

- Bucentaure (80 cañones).

- Santísima Trinidad (130 c.).

- Héros (74 cañones).

- San Agustín (74 cañones).

- Fragata Hortense (40 c.).

- Furet (18 cañones). Almirante Villeneuve (F). Capitán Uriarte (E). Capitán Poulain ( $\mathrm{F}$ ). Capitán Jado Cagigal (E). Capitán de la Meillerie (E). Capitán Demay (F).

\section{Retaguardia:}

- Montblanc (74 cañones). C Capitán Lavillegris (F).

- San Francisco de Asís (74 c.). Capitán Flores (E).

- Duguay-Trouin (74 cañones). Capitán Touffet (F).

- Formidable (80 cañones). Contralmirante Dumanoir (F).

- Rayo (100 cañones).

- Scipion (74 cañones).

- Cornélie (fragata de 40 c.). Capitán Enrique Macdonnell (E). Capitán Cayetano Valdés (E). Capitán Martinenz (F). 
Escuadra de Observación

Estaba dividida en dos divisiones.

Primera División:

- San Juan Nepomuceno (74 c.).

- Berwick (74 cañones).

- Príncipe de Asturias (120 c.).

- Achile (74 cañones).

- San IIdefonso (74 cañones).

- Argonaute (74 cañones).

- Fragata Thennis (32 cañones).

- Fragata Argus (18 cañones).

Segunda División:

- Swittsure (74 cañones).

- Argonauta (80 cañones).

- Algesiras (74 cañones).

- Montañés (74 cañones)

- Aigle (74 cañones).

- Bahama (74 cañones).

- Hermione (fragata 40 cañones)

- Observateur (fragata de 18 c.).

* (F): Nacionalidad francesa

* (E): Nacionalidad española

Esta disposición era bastante acertada. Los tres cuerpos de batalla formarían un conjunto de 28 navíos, que podía sostener el primer choque inglés, mientras que Gravina actuaría en medio de la acción para dar un golpe decisivo al enemigo. Sin embargo, Villeneuve no le permitió actuar aisladamente.

La escuadra inglesa según los planes de Nelson se dividiría en dos columnas de ataque:

\section{Escuadra Inglesa}

Columna de Vanguardia:

Bajo el mando del Almirante Nelson.
- Victory (120 cañones)

- Leviathan (74 cañones)

- Temeraire (110 cañones)

- Neptune (110 cañones)

- Conquerer (74 cañones)

- Sewinthein (74 cañones)

- Ajax (80 cañones)

- Orion (74 cañones)

- Agamenon (64 cañones)

- Minotaur (74 cañones)

- Spartiat (80 cañones)

- Britannia (100 cañones)

- África (64 cañones)
Capitán Churruca (E).

Capitán Camas (F).

Almirante Gravina (E)

Capitán Demieport (F).

Capilann Vargas (E).

.

Capitán Villemadrin (F)

Capitán Pareja (E).

Contralmirante Magon (F).

Capitán Alcedo (E).

Capitán Courrège (F).

Capitán Alcalá Galiano (E).

Capitán Malé (F).

Capitán Croizet (F).
Capitán Epron (F).

Columna de Retaguardia:

Bajo el mando de Collingwood.

- Royal Sovereing (120 cañones) Almirante Collingwood,

Capitán Rotheram

- Mars (74 cañones) Capitán Duff

- Belle Isle (74 cañones)

- Tonnant (80 cañones)

- Bellerephon (74 cañones)

Capitán Hargood

Capitán Tyler

Capitán Cook

- Colossus (74 cañones)

- Achile (80 cañones)

- Polyhemus (64 cañones)

Capitán Morris

Capitán King

Capitán Redmill

- Revenge (74 cañones)

- Swift-sure (74 cañones)

- Defense (74 cañones)

- Thunderer (74 cañones)

- Defiance (74 cañones)

- Prince (100 cañones)

- Dreadnought (100 cañones)

Capitán Rutherford

Capitán Hope

Capitán Stockham

Capitán Durham

Capitán Grindall

Capitán Coun

Una vez definida la formación de la escuadra combinada el Almirante Villeneuve dio orden de partir de la Bahía, lo cual se verificó el día 19 de octubre y al día siguiente toda la escuadra se hallaba fuera de ella.

La escuadra combinada utilizó la conocida "Formación en línea" que consistía en que los buques se colocasen en fila, alineados estrechamente proa con popa, al objeto de disparar los cañones al mismo tiempo, desde los costados de todos los barcos, contra el enemigo, frente al ataque en dos columnas que Nelson resolvió utilizar. Al utilizar esa táctica, y a su vez impedir que Gravina actuase como cuerpo independiente, Villeneuve había firmado la derrota de su escuadra, ya que el ataque dinámico del almirante inglés desconcertó a los navíos españoles y franceses, al envolverlos entre dos fuegos y quedarse algunos de los barcos fuera de la línea de combate y con poca capacidad para maniobrar, debido por un lado, a la impericia de mucho de los

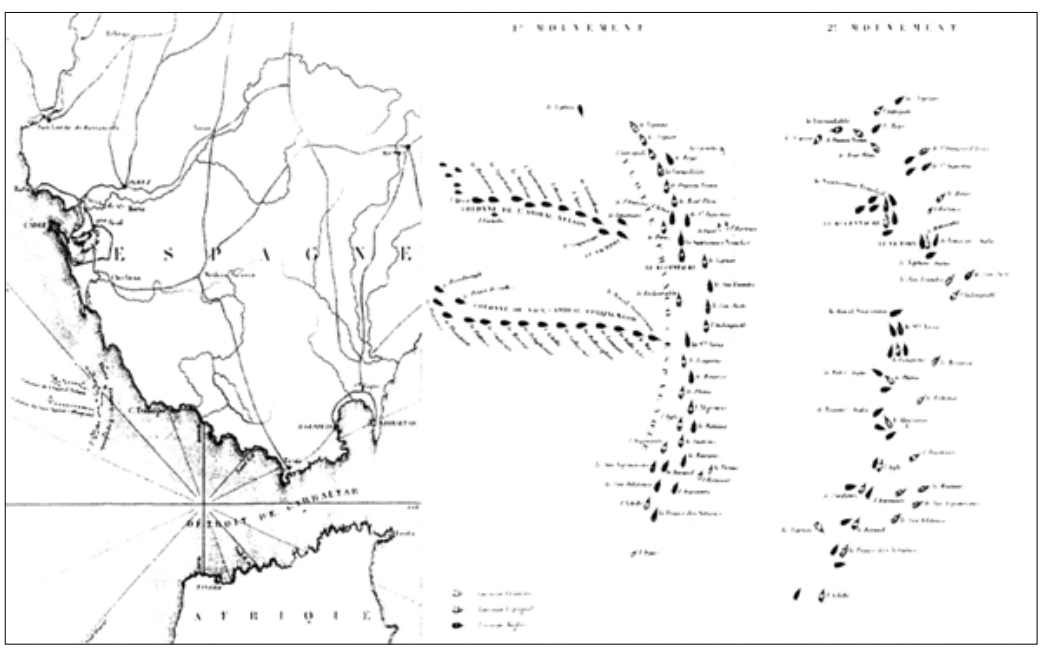

Thiers, M. (1859). Atlas de l'Historie du Consulat et de LÉmpire. París. Plano de situación de la Batalla de Trafalgar.

\begin{tabular}{lcl} 
Fragatas & $\mathrm{n}^{0}$ cañones & Comandantes \\
\hline - Eurygalus & 40 & Blackwood \\
- Syrus & 40 & Prowse \\
- Febus & 40 & Copel \\
- Nayard & 40 & Dundas \\
- Pickle (goleta) & 20 & Lapenotier \\
- Entrepenante (balandra) & 6 & Young
\end{tabular} marineros reclutados por el sistema de leva y por otro, a la falta de ordenes precisas que Villeneuve dio a sus capitanes.
Almirante Nelson,
Capitán Hardy
Capitán Harvey

Capitán Freemantle

Capitán Pellen

Capitán Bayntun

Capitán Pilford

Capitán Codrington

Capitán Berry

Capitán Mansfield

Capitán Laforey

Almirante Northesk,

Capitán Bullen.

Capitán Digby

- Entrepenante (balandra) 6
0
0
0
0
0
0
0
0
5
0
0
0
0
0
0
0
1
4 
Los navíos de la escuadra combinada habían sufrido graves daños. La mayoría estaban desarbolados y de estos consiguieron los ingleses después de su rotunda victoria, apresar 18 navíos. Mientras tanto, el Príncipe de Asturias, único buque insignia que permanecía en la escuadra combinada, puso rumbo a Cádiz remolcado por la fragata Themis. A éste se unieron II navíos: los españoles San Justo, San Leandro, Rayo, Montañés y San Francisco de Asís; los franceses Plutón, Héros, Neptune, Argonaute e Indomptable, más cuatro fragatas.

Parte de la división de retaguardia, cuatro navíos franceses, se salvaron al huir del combate: Formidable, Scipion, Dugay-Trouin y el Mont-Blanc. Aunque días mas tarde fueron capturados y conducidos a Inglaterra por el Comodoro Stracham, después de enfrentarse a ellos frente al Cabo Ortegal.

Las graves pérdidas humanas de las tres escuadras demuestran la dureza del combate: los españoles tuvieron 1.022 muertos y 1.383 heridos; los franceses 3.000 muertos y más de 1.000 heridos; mientras que los ingleses sólo tuvieron 1.600 víctimas, entre ellos 499 muertos y 1.224 heridos.

Al combate le sucedió una situación más extrema; el temporal predicho por los marinos españoles se desató y con bastante fuerza. A consecuencia de la borrasca que duró varios días después del combate, naufragaron yéndose a pique sobre la costa los navíos que habían sufrido las averías más importantes.

Los restos de la escuadra combinada bajo la insignia de Gravina a bordo del Príncipe de Asturias, al finalizar el combate se dirigieron, como ya habíamos dicho, rumbo a Cádiz. Pero como el viento soplaba del sur les impidió entrar el interior de la Bahía, dando fondo en el Placer de Rota a la 1:I5 horas.

Por su parte los navíos ingleses aunque salieron victoriosos de la batalla, con 18 navíos enemigos capturados, también debieron luchar contra el fuerte temporal que siguió al combate. El día 23 consiguieron salir los navíos españoles y franceses para represar los barcos que poseía Collingwood. Se consiguieron recuperar el Santa Ana y el Neptuno remolcados por las fragatas. Pero el salvamento costó el naufragio de otros barcos empujados por el temporal sobre la costa como sucedió al San Francisco de Asís, al Neptuno y al Rayo.

Los ingleses llevaban marinados siete de los buques españoles y franceses desarbolados en dirección hacia Gibraltar. Sin embargo, se vieron obligados a soltarlos en parte, al arreciar el temporal. Los otros, fueron a estrellarse sobre la costa durante la tempestad al día siguiente. Uno de ellos fue el Santísima Trinidad que se hundió el día 24 a consecuencia del agua que entraba en su casco por los múltiples destrozos que sufrió durante la batalla.

El vendaval del S.O, viento característico de esta costa aumentó, agitando violentamente el mar. Los ingleses teniendo también sus navíos con averías importantes y sin puerto a donde ir adoptaron la decisión de soltar los barcos enemigos desarbolados que llevaban a remolque, porque en caso contrario no hubiesen podido enfilar el Estrecho de Gibraltar. La escuadra inglesa llegó a ese puerto con 4 barcos de los 19 capturados (Bahama, San Juan Nepomuceno, Ildefonso y el Switsure francés ).

Haciendo un recuento final, podemos decir que se hundieron los siguientes navíos:

\begin{tabular}{ll} 
Nacionalidad Francesa & Nacionalidad Española \\
\hline - Aigle & - Argonauta \\
- Berwick & - Monarca \\
- Bucentaure & - Neptuno \\
- Fogueux & - Rayo \\
- Indomptable & - San Agustín \\
& - San Francisco de Asís \\
& - Santísima Trinidad
\end{tabular}

Cuatro fueron los navíos que los ingleses llevaron remolcados a Gibraltar: San Juan Nepomuceno, Bahama, San Ildefonso y Swiftsure francés, de los cuales los dos últimos debieron al parecer ser hundidos por su mal estado. A los que hay que añadir los cuatro navíos de la división de Dumanoir que huyeron del combate, apresados días después por los ingleses y conducidos a Inglaterra: Formidable, Montblanc, Scipion y Duguay- Trouin.

De este modo, diez barcos de la Escuadra Combinada entrarían definitivamente en el puerto de Cádiz:

\begin{tabular}{ll} 
Nacionalidad Española & Nacionalidad Francesa \\
\hline - Montañés & - Algesiras \\
- Príncipe de Asturias & - Argonaute \\
- Santa Ana & - Héros \\
- San Justo & - Neptune \\
- San Leandro & - Plutón
\end{tabular}

En los días siguientes a la batalla aparecieron gran cantidad de restos de los navíos destrozados, así como multitud de cadáveres en la costa de Cádiz. Muchos fueron los náufragos que fueron auxiliados por la población de la Bahía de Cádiz. Un documento que refleja significativamente esta situación, es el Acta Capitular del Cabildo de El Puerto de Santa María del día 16 de noviembre de 1805 (Tomo I | 8. Folio 490. Legajo 64) y de la cual reproducimos a continuación una parte:

\footnotetext{
“... Las resultas de un honroso combate y los estragos de un temporal continuado presentaron a la vista varios buques desarbolados y rotos que no pudiendo tomar el Puerto por su estado y por el tiempo dieron sobre nuestra costa. En estas circunstancias vimos precipitarse el Pueblo al socorro de sus compatriotas, de sus aliados y aun de sus enemigos: todos llevados de una gloriosa competencia querían aventurarse en el trabajo. La matrícula llamava a hacerse a el Mar para auxiliar con sus embarcaciones pero imposibilitava su ardor el mal estado de la Barra: A vista de ese inconveniente mar-
} 


\begin{abstract}
chavan en tropa a la costa y exponiendo sus vida a la emulación de su jefe, nada les quedó que hacer para salvar las tripulaciones..."
\end{abstract}

Además de las labores se rescate de los supervivientes, se establecieron una serie de actuaciones para recuperar los restos de los navíos que se pudieran reutilizar (cabos, lonas, jarcias, cañones, etc.). Podemos citar a modo de ejemplo, el siguiente dato extraído del Libro de Actas de la Junta Municipal de Cádiz, en el Acta de Conferencias celebrada el día 24 de octubre de 1805 que cuenta como se establecieron una serie de disposiciones, entre ellas, recorrer la costa para recoger los pertrechos navales que pudieran reutilizarse. Para almacenarlos se estableció un depósito situado en el "Bentorrillo del Chato", emplazado en el Camino del Arrecife entre las poblaciones de Cádiz y San Fernando.

La Batalla de Trafalgar significó sin duda la decadencia de la Marina Española. Muchos de los grandes "navíos de línea" que surcaron los mares, con la pérdida de las colonias americanas terminarían pudriéndose en los astilleros españoles por falta de carena.

\section{Análisis arqueológico}

Este apartado ha consistido en los siguientes puntos:

- Recopilación de los datos relativos a las actuaciones arqueológicas realizadas hasta la fecha en el litoral de Cádiz y Huelva: Hemos efectuado un recorrido cronológico de todas las intervenciones arqueológicas realizadas en la zona objeto de nuestro estudio, que están en relación con los hallazgos subacuáticos de artillería naval, aunque debemos decir que no han sido muchas, en parte debido a la escasez de personal cualificado en los primeros tiempos, y en segundo lugar, a los presupuestos económicos más altos que necesitan estas actividades en comparación con la Arqueología terrestre.

- Recopilación de información sobre los hallazgos arqueológicos subacuáticos que existen en el litoral gaditano y onubense, tanto restos de cascos de navíos como restos de artillería naval. Para la elaboración de este apartado se ha contado con los datos de las Cartas de Riesgo de la Provincia de Cádiz y Huelva, elaboradas por Josefa Martí y Milagros Alzaga, respectivamente. Otra fuente informativa fundamental han sido las noticias orales de buceadores deportivos que han señalado zonas de concentración de restos arqueológicos subacuáticos. Estos restos pueden ponerse en relación con las posibles zonas de hundimiento de los navíos naufragados a consecuencia del combate de Trafalgar y del temporal que sobrevino después. El resultado ha sido la elaboración de un mapa de distribución de restos de navíos aparecidos en las costas de Cádiz y Huelva , así como otro de cañones de hierro y bronce.

La información obtenida sobre dichos restos materiales ha sido reflejada en un mapa de localización, confrontándose con las zonas de naufragios que nos ha proporcionado la información documental, obtenién-

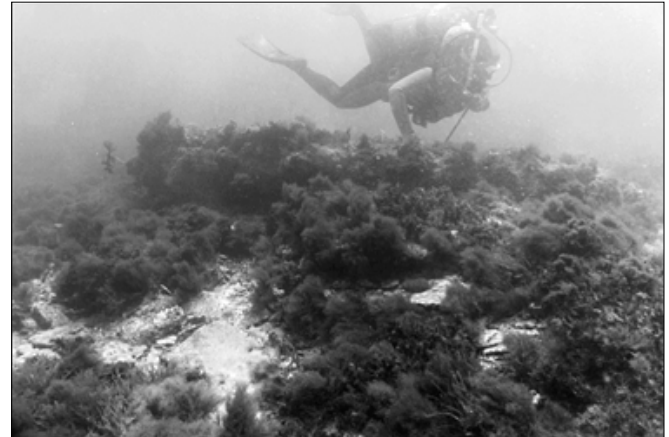

A pesar de que cañones y proyectiles, por tratarse de navíos de guerra, sean junto con los restos de madera del casco los vestigios más significativos que puedan aparecer, hay que tener en cuenta que existirán asociados otros indicadores de la cultura material: instrumental quirúrgico, instrumentos de navegación, elementos metálicos integrantes de los uniformes militares (botones, hebillas, etc.), armamento (fusiles, bayonetas, espadas, etc.), vajilla común y de lujo de cerámica o cristal, así como elementos de ocio (pipas de caolín, dados, etc.).

\section{Conclusiones}

Es necesario puntualizar que las fuentes documentales consultadas son de origen y naturaleza distinta. A modo de ejemplo diremos que se han consultado monografías del siglo XIX, Protocolos Notariales del Departamento de Marina de San Fernando del año 1805, Actas Capitulares, Cartas Náuticas, Derroteros, artículos de publicaciones periódicas tanto actuales como de la misma época, así como se han realizado consultas en la red Internet.

Con toda la información obtenida, además de documentar los naufragios producidos a consecuencia de la Batalla de Trafalgar, hemos conseguido obtener una visión de la realidad del ramo de Marina en el siglo XVIII, analizando desde los sistemas de construcción navales y arsenales existentes, hasta el sistema de reclutamiento de marinería denominado "Matrícula de Mar"; así como el panorama político de Europa, los pactos y alianzas entre las potencias europeas que produjeron en última instancia el desastre de Trafalgar

La búsqueda documental realizada para este proyecto de investigación acerca de la Batalla Naval de Trafalgar ha tenido un resultado de un total de 106 referencias documentales encontradas. Se pueden dividirlas en dos grandes bloques, de una parte las procedentes de centros archivísticos y de otra las procedentes de centros bibliotecarios.

En los Archivos se han encontrado referencias a la batalla en la Actas Capitulares con fecha de 1805, de los respectivos Ayuntamientos de las ciudades de Cádiz,
Restos de artillería localizados en el área de la Bahía de Cádiz. 


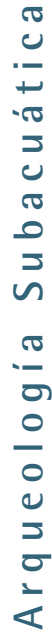

Parte de averías y pérdidas sufridas por la Escuadra Inglesa durante el combate de Trafalgar según las fuentes de información españolas.

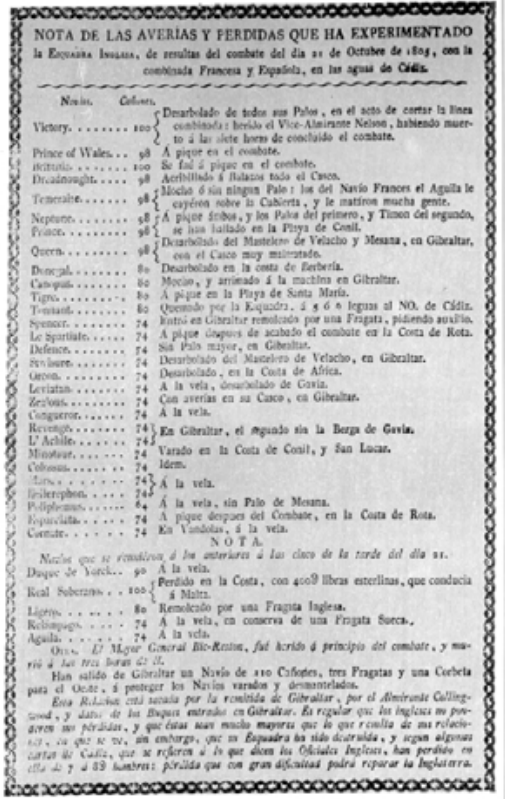

El Puerto de Santa María y San Fernando. De éstas las que nos aportan más datos sobre las labores de rescate que se organizaron para socorrer los náufragos de los navíos es el Acta Capitular de 1805 del Cabildo del Puerto de Santa María. Sin embargo, existe un silencio en todas ellas en cuanto a la indicación concreta en nuestro litoral del lugar de hundimiento de los navíos.

Las Actas Capitulares consultadas, si bien no se especifican en ellas los lugares donde se produjeron los naufragios, si son una buena fuente para ver el lado humano de la batalla, catástrofe que supuso en Cádiz el ver durante días a causa del fuerte temporal el salir los cadáveres y numerosos pertrechos navales arrojados por el mar a las costas del litoral gaditano.

Con respecto al otro gran bloque de documentación analizado y que se halla depositado en centros bibliotecarios, hay que decir que la búsqueda ha sido bastante fructífera. Se han encontrado abundantes referencias sobre el combate tanto del s. XIX como de este presente siglo en el área de la Bahía gaditana. Ello se debe en gran medida a la labor recopilatoria que efectuó el erudito gaditano Augusto Conte y Lacave, al escribir su libro En los días de Trafalgar en año 1975. Los fondos de su biblioteca privada pasaron a formar parte de la Biblioteca de Temas Gaditanos, aunque gran parte de la colección de manuscritos y folletos que poseía no fueron traspasados a los fondos de esta biblioteca, con lo cual desconocemos su actual ubicación. Existen otras bibliotecas como la Biblioteca del Almirante Lobo, la Biblioteca del Real Observatorio de Marina de San Fernando y la Biblioteca del Casino Gaditano. En ellas hemos encontrado ejemplares de obras escritas en el siglo pasado que hacen referencia al famoso combate naval, entre ellos: M. Marliani, M. Thiers, A. Alcalá-Galiano, Lasso de la Vega, Francisco de Paula Pavía, entre los autores españoles; Capefigue, Desdevizert, Leon Guerin, entre los autores franceses y William James entre los autores ingleses.
De todas estas monografías escritas el siglo pasado, pocas dan referencias concretas sobre el lugar donde se produjeron los naufragios de los navíos de la escuadra combinada. Entre ellos Leon Guerin en su Histoire Maritime de la France escrito en el año I85।. En esta obra, las referencias a zonas de naufragios difiere en algunos casos de las fuentes españolas,

Otro autor que también nos proporciona algunos datos sobre los hundimientos de los buques es el ingles William James, en su obra The Naval History of Great Britain from the declaration of war by France in 1793, to the ascensión of Georges IV escrita en el año I845. En ella encontramos varias referencias acerca de los buques náufragos.

Otro tipo de documentación consultada y en las que en algunas de ellas aparecen algunos datos que nos interesan, son las publicaciones periódicas de la época. Entre ellas la publicación oficial era la "Gazeta de Madrid", la cual aporta una importante información sobre los preliminares de la batalla, así como los movimientos de las dos escuadras enemigas meses antes del combate. En el número 89 con fecha del 5 de noviembre de La Gazeta de Madrid. Años 1805-1806 además de dar noticia sobre el "represamiento" de los navíos Santa Ana y Neptuno, se relata como un temporal del sur-sureste desamarró los navíos Asís y Neptuno, que vararon en la noche del día 23 en la costa de El Puerto de Santa María.

Entre las publicaciones locales de la ciudad de Cádiz están El Diario Mercantil y El Parte Oficial del Vigía de la Torre de Tavira. En el ejemplar del jueves 31 de octubre de la primera publicación sólo aparecen unas simples reseñas sobre el combate frente al cabo Espartel, como se conoció en un primer momento la batalla. Por otro lado, en el Parte de Vigía de la Torre de Tavira se recoge la formación de la escuadra combinada al partir en busca de la escuadra inglesa, con el respectivo porte y nombre del capitán, así como la nacionalidad de cada navío. No obstante, hay que decir que después de la batalla sólo se hacen leves referencias, quizás, al objeto de ocultar a la población el desastre que supuso el enfrentamiento con los ingleses.

Este silencio de la prensa local, a pesar de que los gaditanos fueron testigos de primera fila, es extensivo tanto a la prensa nacional como a la prensa francesa. Ello se debe a la intención de los dos gobiernos, como dijimos anteriormente de silenciar el desastre. Al mismo tiempo para desvirtuar la realidad los españoles publicaron un folleto denominado "Perdidas y Averías padecidas por la Escuadra Inglesa con motivo del combate que sostuvo con las combinadas francesa y española sobre las aguas de Cádiz en 21 de octubre de 1805", en el cual se inflaron las pérdidas que tuvo la escuadra inglesa, la cual cifraban en nueve navíos.

Pero sin lugar a duda la información más fiable sobre el lugar donde se produjeron los naufragios la podemos encontrar en la documentación oficial generada a causa del combate. Además de los partes oficiales, escritos bien por los capitanes supervivientes o bien 
por los oficiales sucesores en el mando en caso de su muerte, existen unos partes sobre las actuaciones emprendidas para las labores de socorro que se efectuaron tanto para el salvamento de los náufragos en un primer momento, como de los pertrechos navales que aun pudieran reutilizarse.

La trascripción de estos partes fueron recopiladas por Eduardo Lon Romeo en su libro Trafalgar (Papeles de Campaña de 1805) publicado en 1950. En ellos hemos encontrado información acerca de lo sucedido en particular a cada navío de nacionalidad española, como dijimos anteriormente, en los partes escritos por los oficiales al mando para relatar los acontecimientos del combate. Con respecto a la información general de lo sucedido a los navíos de la escuadra combinada, tanto españoles como franceses, así como de las labores de rescate que se organizaron posteriormente han sido extraídas de los siguientes documentos:

- "Noticia del Estado en que se hallan los buques de la escuadra combinada del mando del vicealmirante Villeneuve y del teniente general D. Federico Gravina de resulta del combate último y del temporal que siguió". ...." (Parte de A. Escaño. Cádiz, a 29 de octubre de 1805). En Trafalgar (Papeles de campaña de 1805) / Eduardo Lon Romeo

- "Linea de batalla en orden inverso de la Armada combinada española y francesa , y de los sucesos acaecidos a cada buque en particular, e indicado según las noticias que se han podido adquirir de comandantes y oficiales" (Parte de A. Escaño. Cádiz, a 8 de Noviembre de 1805). En Trafalgar (Papeles de campaña de 1805) / Eduardo Lon Romeo

- "Resumen de las faenas de mar dirigidas por oficiales de marina de la escuadra y departamento, executadas por los marineros de uno y otro destino en los días desde el 20 hasta el 27 de octubre último, para evitar asi la perdida de los navíos que de resultas del combate del 21 y temporales fondearon en riesgo sobre Rota, como para socorrer los náufragos de los que se perdieron en la costa de Levante y de Poniente del puerto de Cádiz". En Trafalgar (Papeles de campaña de I805) / Eduardo Lon Romeo.

Otro autor que ha recopilado bastante información sobre la batalla es Pelayo Alcala-Galiano, hijo del autor de Recuerdos de un Anciano y nieto del brigadier Dionisio Alcala-Galiano, muerto a bordo del navío Bahama, apresado por los ingleses en el enfrentamiento. Este autor escribió en el año 1909 un libro sobre lo sucedido no sólo en la batalla, sino también los preliminares. Esta obra en dos tomos denominada El Combate de Trafalgar recoge abundante información entre la documentación que reproduce, entre ellas sobre todo cartas de los respectivos ministros y embajadores de España y Francia. No obstante debemos decir, que si bien toda esta documentación es fundamental para comprender la evolución política de los acontecimientos que tuvieron su punto final en el encuentro final de las dos escuadras frente al Cabo de Trafalgar, no nos aporta datos acerca de las posibles zonas donde se hallan los navíos naufragados.
Aunque si es una obra fundamental entre la bibliografía del tema que nos ocupa.

Un autor mencionado anteriormente y a través del cual hemos encontrado alguna documentación interesante reproducida en su libro En los Días de Trafalgar, es Augusto Conte y Lacave. En su obra se encuentran algunos documentos que poseía en su colección privada, o que formaban parte de otras colecciones particulares de ciudadanos de la ciudad de Cádiz. Algunos de estos documentos son:

- Relación de la escuadra que ha comenzado a salir de la Bahía de Cádiz el 19 de octubre del presente año de 1805. (Colección Alvaro Picardo)

- Dos Carta de Juan Creagh de Lacy, coronel del regimiento de la corona al duque del infantado, con fecha de 25 y 29 de Octubre de 1805 respectivamente. (En los días de Trafalgarl Augusto Conte y Lacave.). En ellas relata las labores de rescate que se hicieron para salvar los hombres y pertrechos navales de los navíos naufragados en las costas de El Puerto de Santa María: Neptuno y San Francisco de Asís entre los españoles, e Indomptable y Aigle, entre los franceses.

- "Relación fechada en I de noviembre de 1805, que recoge la información que en Cádiz se tenía de la acción de Trafalgar en aquella fecha".: En los días de Trafalgarl A. Conte y Lacave.

- "Perdidas y Averías padecidas por la Escuadra Inglesa con motivo del combate que sostuvo con las combinadas francesa y española sobre las aguas de Cádiz en 21 de octubre de 1805". En los días de Trafalgarl A. Conte y Lacave.

- Carta de Villeneuve a Gravina con fecha del 7 de octubre de 1805 con motivo del Consejo de Guerra que se celebraría a bordo del Bucentaure para decidir la salida de la escuadra combinada. (Procedente del Archivo Croquer).

Entre los fondos de la Biblioteca de Temas Gaditanos hemos podido consultar gran parte de la bibliografía utilizada por Conte y Lacave. Entre ellas es importante mencionar el dato que Conte reseña en su obra y que lo recoge Miguel Mancheño y Olivares en la biografía de Pedro Cabrera y Yuste, incluída en su obra Galería de Arcobricenses llustres, sobre el recate de gran parte de la artillería del Neptuno, San Francisco de Asís e Indomptable. Aquí se aporta la información de que al producirse los naufragios de estos navíos tan cerca de la costa de El Puerto de Santa María, fueron posibles las labores de extracción de parte de su artillería, para ser reutilizadas:

"Con harto dolor dejó de concurrir Cabrera aquel combate. Ayudante a las órdenes del $\mathrm{Ge}$ neral del Departamento, fue destinado en previsión de posibles contingencias a mandar en la costa del Puerto de Santa María, y en efecto cuando perdida la batalla, desarbolados, acribillados de balazos y sin gobierno los pocos na- 
víos que sobrevivieron al desastre fueron arrojados por la tempestad sobre aquellas costas, multiplicándose el bravo Capitán de Fragata, casi sin gente ni recursos organizó el salvamento....por el que no recibió premio ni remuneración alguna, ni tampoco por haber salvado toda la artillería del «Neptuno» y gran parte de la de los otros dos navíos (San Francisco de Asís e Indomptable), con inmensa cantidad de jarcias, cables, velamen y aparejos, en cuyas operaciones estuvo ocupado veinte y dos meses...."

De este texto podemos deducir que las labores de rescate de los pertrechos navales de esos tres navíos naufragados, y de los cuales dos de ellos el Neptuno y el San Francisco de Asís se hallaban muy cerca de la costa, fueron bastante intensas porque como cuenta Mancheño y Olivares le llevaron a Pedro Cabrera el tiempo de casi dos años para concluirlas, con lo cual pocos restos de artillería naval se podrían hallar in situ, según esta información. Como dato curioso, hay que decir que en el Archivo Histórico Municipal de El Puerto de Santa María se conserva el supuesto diario de a bordo del Capitán del navío español Neptuno, Cayetano Valdés, en el cual éste relata los sucedido a su barco desde que finalizó la batalla y fue capturado por los ingleses, hasta que naufragó en las costas de El Puerto de Santa María.

En la Biblioteca de Temas Gaditanos además de las monografías del siglo XIX se encuentra documentación original de la época:

- DIARIO de Algeciras: Noticias del Campo de Gibraltar, extractadas de los partes que el Vigía de Torre Carbonera pasa al Excmo. Señor General en Gefe de este Exercito y Campo. No 77,81 y 84. Octubre 1805

- COS, Manuel. Oración fúnebre que en la exequias celebradas el día 21 de Noviembre de 1805. Cádiz: Casa de la Misericordia, 1805.

- ORACIÓN fúnebre que en las solemnes exequias del Excmo S.R. D. Federico Gravina, caballero de la Real y distinguida orden española de Carlos III, gentil hombre de cámara de S.M. con exercicio, Capitan General de la Real Armada \& C. Celebradas por su albaceas en la Iglesia de RR.PP. Carmelitas Descalzos de la Ciudad de Cádiz a XXIX de Marzo de MDCCCVI, Dixo el Doctor José Ruiz y Román, cura propio del Sagrario en la Santa Catedral de ella, Examinador Sinodal de su Obispado, Teólogo Consultor y Examinador de la Nunciatura Apostólica en estos Reynos. Cádiz: Reimpresa en dicha ciudad por Don Nicolás Gómez de Requena, Plazuela de las Tablas, 1806.

- CARTA del Almirante Villeneuve a Bonaparte. [s.d.]

Aunque hay que decir que otros muchos documentos manuscritos que poseía en su colección, no se encuentran en la actualidad entre sus fondos.

A lo largo del siglo XIX se ha publicado mucho sobre la Batalla de Trafalgar, tanto por parte de autores nacionales como extranjeros, sin embargo han sido escritas desde un punto de vista histórico, analizando las causas, el desarrollo y las consecuencias que tuvo. El planteamiento se ha hecho desde un punto de vista político y humano, pero nunca hasta la fecha se había planteado analizarlo desde un punto de vista arqueológico, como sucede en el "Proyecto Trafalgar", puesto en marcha por el Centro de Arqueología Subacuática y del cual forma parte nuestro proyecto de documentación como fase inicial. Por ello nuestro objetivo ha sido seguir el rastro de los sucedido a los navíos naufragados.

En la documentación consultada hemos encontrado referencias a lo sucedido con esos navíos, no obstante no han sido todo los numerosas y fructíferas que hubiéramos deseado, además de ser poco unánimes en cuanto a la indicación de las zonas donde se produjeron los hundimientos a causa del fuerte temporal que se desató durante varios días después de la batalla. Por ello hemos optado por efectuar una agrupación de todas las reseñas encontradas en las fuentes documentales consultadas y en las cuales se menciona con referencias geográficas las posibles áreas de hundimiento, las cuales han sido definidas utilizando también cartografía de la época, así como derroteros y cartas náuticas actuales.

A través de este listado, hemos podido comprobar que las referencias sobre las zonas de hundimiento para los navíos naufragados a consecuencia de la Batalla de Trafalgar, en general, no son uniformes. No obstante, debemos decir que para algunos navíos sí presentan mayor unanimidad.

A partir de este análisis comparativo podremos plantear, aunque siempre con reservas y en espera de que en la fase de prospecciones subacuáticas del Proyecto Trafalgar se confirmase, la hipótesis de que puedan corresponder con algunos de los navíos objetos de nuestro estudio.

La metodología planteada para llevarlo a cabo, es confrontar la información de los hallazgos arqueológicos subacuáticos (cañones, restos de madera o forro de cobre del casco del buque, etc..) de los que tenemos constancia, bien por actuaciones arqueológicas o bien por referencias orales, con las áreas que hemos delimitado anteriormente como posibles zonas de hundimiento de algunos de los buques, al objeto de ver el grado de concentración de restos arqueológicos en esas determinadas áreas

La siguiente fase del Proyecto Trafalgar consistirá en el planteamiento de actuaciones arqueológicas, tanto en los pecios que tradicionalmente han sido adscritos a este enfrentamiento entre la escuadra inglesa y franco-española, como en las zonas apuntadas en esta fase documental como posibles áreas de naufragios de los navíos, que a consecuencia de los daños sufridos en el combate primero y posteriormente por el temporal que sobrevino a la batalla, se produjeron. El objetivo último es clarificar mediante una metodología arqueológica en la medida de lo posible, la identificación y datación de los restos materiales, para luego facilitar su conservación como parte integrante de nuestro Patrimonio Arqueológico Subacuático. 